\title{
THE HISTORY OF THE IDEAS ON THE FUNCTION OF THE BICEPS BRAGHII MUSGLE AS A SUPINATOR
}

by

\author{
J. G. BEARN
}

\section{INTRODUCTION}

Before Leonardo da Vinci the movement of supination was always given as a function of the muscle now called the brachio-radialis. Leonardo, in a series of annotated drawings made between 1505 and 1510 , made it abundantly clear he understood that the biceps brachii was the principal supinator, in addition to its action as a flexor of the elbow. However, because he was neither a teacher of anatomy, nor did he publish his notebooks, this observation remained unnoticed, and it was not until 200 years later that this action was rediscovered by Cheselden and recorded in the first edition of his textbook in 1713 . Seven years later in 1720 Winslow read a paper to the Académie Royale des Sciences also describing this action of the biceps as if it were his own discovery and included it in the first edition of his textbook in 1732 , giving a very clear description of the movement. This supinating action of the biceps, although briefly noted in most textbooks published after 1732 was not re-examined in detail until Duchenne's classic account in the Physiology of Motion published in 1867, to which little has been added to this day.

\section{Galen (c. A.D. 129-20I)}

The traditional method of studying muscle action, as described by Galen in De Usu Partium, was the examination of dissections accompanied by pulling on the dissected muscle, and confirmed by the palpation of the muscle belly and tendon in the living subject during active movement of the joint. Galen's first and most comprehensive treatise on anatomy, De Usu Partium, was completed by A.D. I 75. His second, De Anatomicis Administrationibus, was completed in A.D. I 77, and has recently been translated by the late Dr. Charles Singer. It is essentially a practical book, probably based on a shorthand record of a series of public lectures given on anatomy in Rome when he became Physician to the Emperor in A.D. I 76. In these two books Galen deals with the muscles of supination and pronation and gives a good account of their anatomy and attachments. He also describes the two anterior muscles which flex the elbow (i.e. the biceps and the brachialis). However, as Vesalius (I543) points out, he contradicts himself in his two books. In De Usu Partium he describes how the biceps is not only a flexor but also bends the forearm outwards while the brachialis flexes and bends the arm inwards. In De Anatomicis Administrationibus, he states the opposite view, that the biceps flexes the elbow bending the arm slightly inwards while the brachialis flexes, bending the arm slightly outwards. 


\section{The History of the Ideas on the Function of the Biceps Brachii Muscle as a Supinator}

$\mathrm{He}$ then goes on to say that if both muscles perform their function correctly the bend of the articulation is inclined neither to right nor left', but no mention is made of supination as a function of the biceps.

In De Anatomicis Administrationibus the brachio-radialis muscle is described, and Galen says that by it, 'this part is turned inwards', Singer interprets this as flexion of the elbow. The pronator teres, pronator quadratus and supinator muscles are all described and their functions correctly given. A second supinator muscle is described, Singer's translation reads: 'The yet longer and more fleshy muscle which lies altogether above this [i.e. the supinator] also moves the hand into the supine position. ...' Singer suggests that this refers to the extensor carpi radialis longus and brevis, although it seems probable that Galen is here referring to the brachio-radialis.

Galen thus had a very clear idea of the muscles concerned with flexion of the elbow, and with supination and pronation, except that he did not recognize the supinating function of the biceps. He also believed that straight flexion of the elbow could only be produced by the combined action of both the biceps and the brachialis muscles acting together. This point was finally corrected by Vesalius (1543), who showed that either muscle could produce straight flexion.

Galen's works, like so many other ancient writings, were kept alive by Arabic translations, and were then rendered into Latin between the eleventh and fourteenth centuries. Avicenna (980-1037) briefly epitomizes Galen's account of the muscles, condensing them into a few pages. Mundinus (c. 1270-1326) carries this condensation to almost complete omission, and describes only the muscles of the anterior abdominal wall and the thorax. The muscles of the limbs are ignored completely, the Public Anatomies at this time being concerned only with the contents of the abdomen, thorax and head. Berengario da Carpi (c. I460-1530) may be considered as a link between the medieval anatomy of Mundinus and the modern period of anatomy ushered in by Vesalius in I 543 . His commentary on Mundinus was published in $152 \mathrm{r}$, and his short introduction to anatomy (Isagogae breves) a year later, two years after Leonardo's death. However, Berengario's treatment of the limbs, apart from a plate illustrating the superficial veins and muscles shows little advance from the teaching of Mundinus and contains no account of the individual muscles.

\section{Leonardo da Vinci (1452-1519)}

The annotated drawings made by Leonardo da Vinci make it abundantly clear that he understood not only the supinating action of the biceps, but also that the brachio-radialis can act as a flexor of the elbow. Leonardo da Vinci's achievements as an anatomist have been discussed many times, and it is only necessary to say that of all his anatomical drawings, those of the muscles are the finest and the most accurate. They were produced between 1505 and 1510 mainly during his second Milanese period, when he had obtained a copy of De Usu Partium. The anatomical studies made during this phase were largely on osteology and myology, and are much superior to the drawings of earlier periods. It was during this time in Milan that he met Professor Marcantonio 


\section{F. G. Bearn}

della Torre, who died of plague in $15 \mathrm{I}$. In his notes Leonardo describes plans for the production of a Treatise on Anatomy, and this has given rise to the tradition started by Vasari but without foundation, that he was to collaborate with Torre in this project. It was during this period too that Leonardo had some facilities for dissecting the human body.

Anatomists are indebted to Dr. Charles D. O'Malley and Dr. J. B. de C. M. Saunders for publishing the anatomical drawings of Leonardo da Vinci, together with a translation of his notes, which fill all the available spaces between the pictures. The account of Leonardo's views on the biceps and supination are taken from this translation. Before describing them, it must be emphasized that the schism between anatomy and physiology did not occur until the nineteenth century, up to then the study of structure and function was one, and all anatomists had a teleological approach to the structures they dissected. Many of Leonardo's drawings are intended to illustrate the function of the part as much as its anatomy. This is well illustrated in the drawings in which the muscles are replaced by cords, so that their function and also their relationship to each other may be better understood.

The biceps muscle and its function as a supinator is shown in no less than three plates, one of which has five separate drawings on it. They were drawn between 1505 and $\mathrm{I}_{5} \mathrm{I} 3$, three being dated about $\mathrm{I}_{5} \mathrm{I}$. An earlier plate (Plate I), dated about I 504 shows six drawings of the front of the arm, and a study of these makes it clear that he had not yet appreciated the function of the biceps. The first drawing shows the brachialis correctly. The second shows the biceps muscle superimposed on the brachialis, but the tendon of biceps crosses deep to the brachialis muscle, and the radius and ulna appear to be transposed. The third sketch has more muscles added and is even more confusing.

However, by the beginning of his second Milanese period in 1505 Leonardo has understood this action. On a plate (3) in which a number of embryological drawings were added years later, he shows two drawings of the bones of the upper limb with the brachialis, biceps and pronator teres muscles drawn to demonstrate their functions.

The plate is headed 'On all the forces and action of the forearm, that is to say which muscle rotates, which flexes it.' He goes on to say,

the muscle (biceps) serves to rotate the bone (radius) through half a revolution . . . and the second muscle (brachialis) is made to bend the arm into any degree of angle. It is attached to the humerus and to the non-revolving bone (ulna) of the arm. It is very strong because it has to support a very large weight. It cannot rotate the arm like the muscle (biceps) and the muscle (pronator teres) in opposite motion like the cords of a trephine, an instrument for drilling.

These two muscles (Biceps and pronator teres) are arranged by their Author that they may

\footnotetext{
Plate I-Drawings of upper limb muscles by Leonardo (c. I 504) (QV $5 r$ ). This plate shows that Leonardo has not yet understood the supinating action of the biceps. Ist drawing shows the brachialis muscle. 2nd drawing shows the biceps and is full of errors. The biceps tendon passes deep to the brachialis. The remaining drawings are even more confusing.

Plate 2-Two sketches of the elbow region with the biceps, brachialis, triceps and pronator teres muscles added, by Leonardo (c. I510-12) (QV $7 \mathrm{v})$. These two sketches distinguish between the action of the brachialis as a pure flexor, and the biceps as supinator.
} 


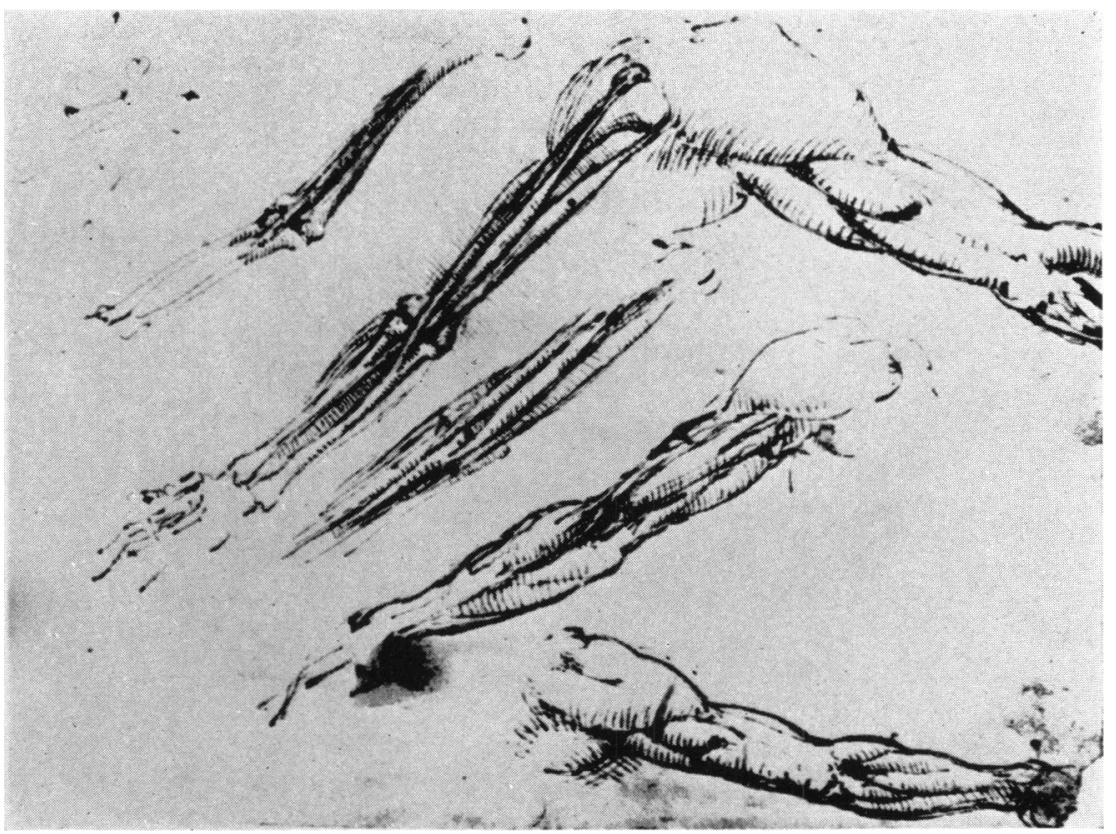

Plate I

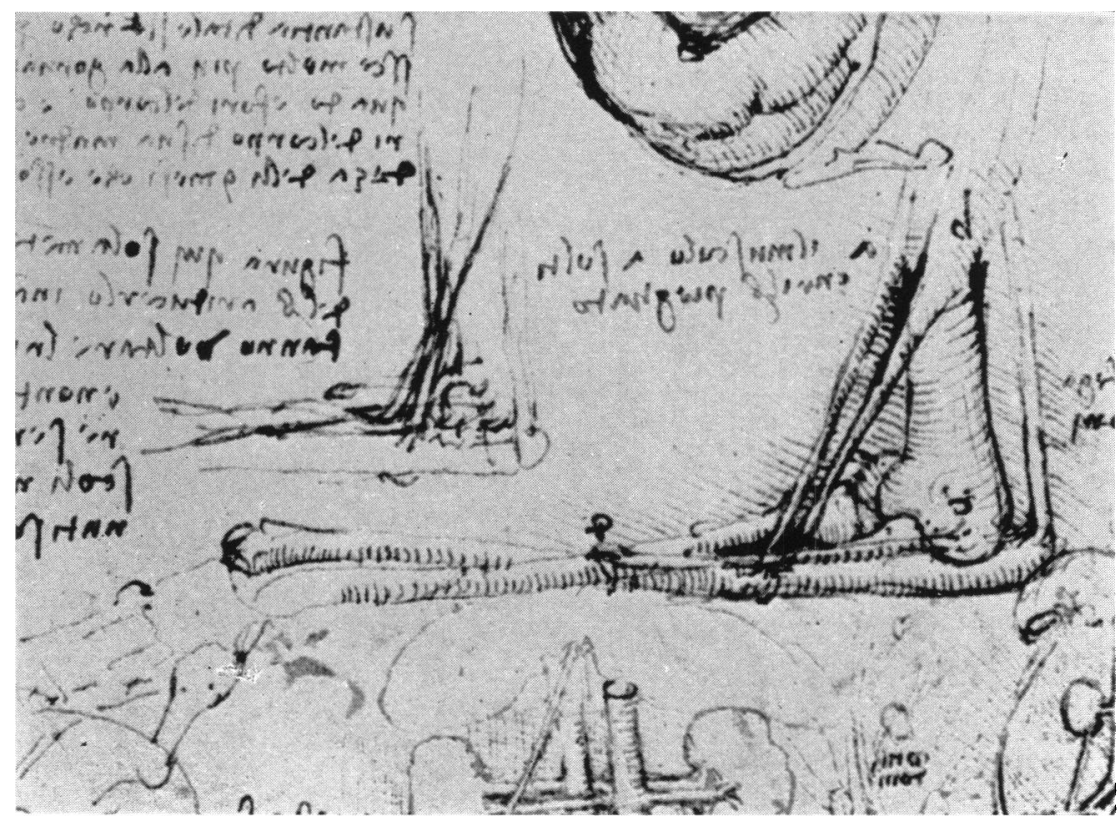

Plate 2 


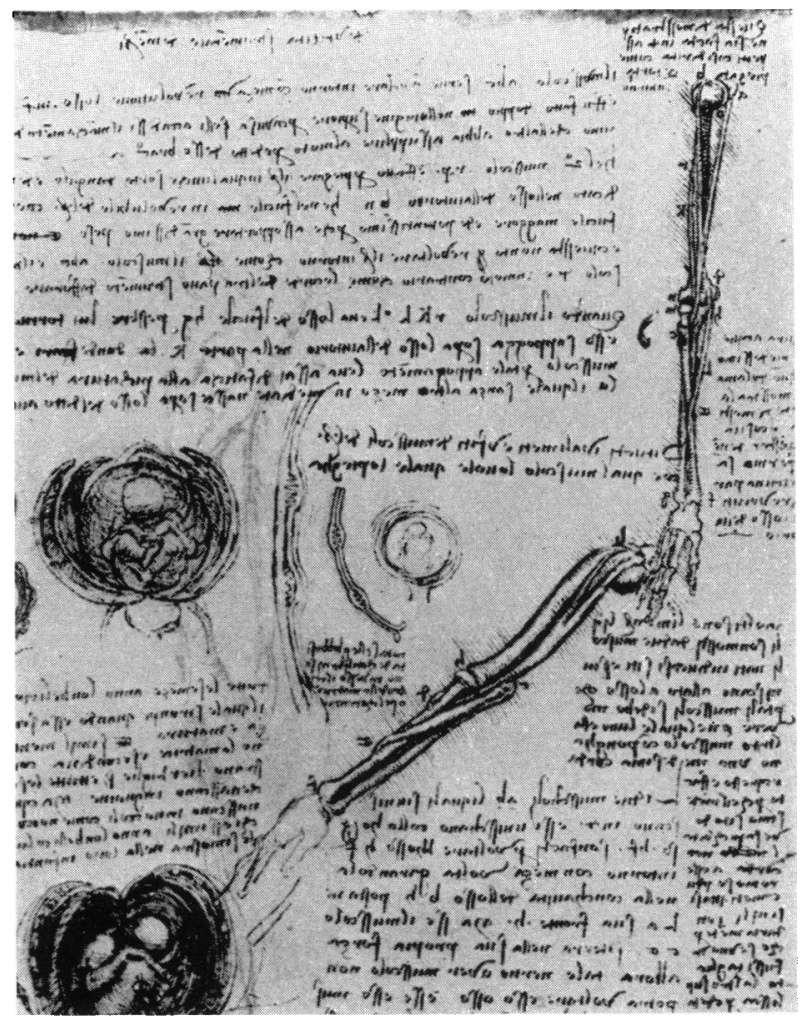

\section{Plate 3}

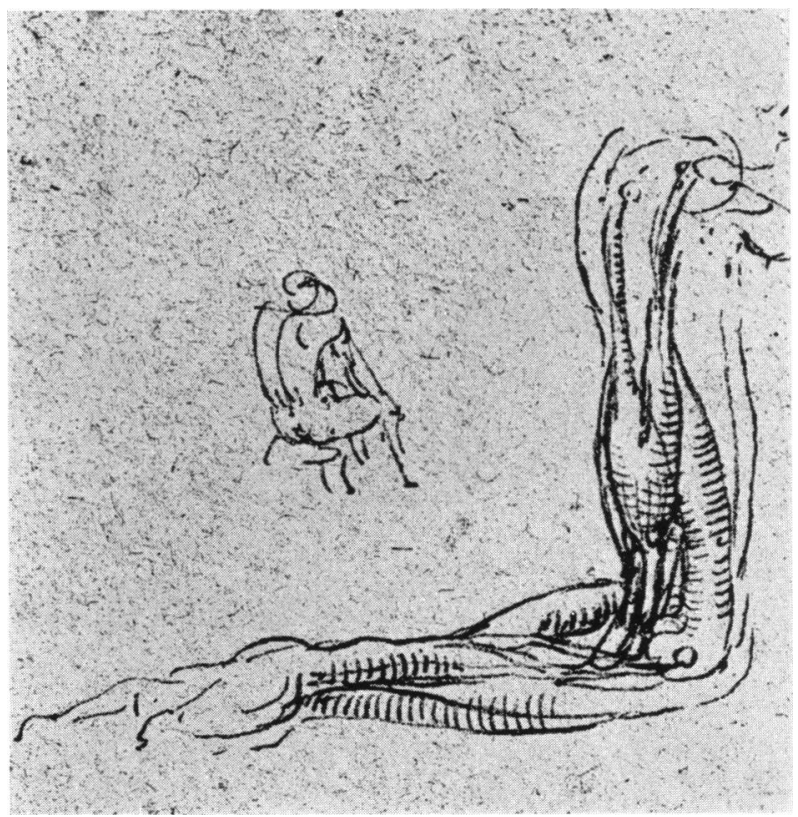

Plate 4 


\section{The History of the Ideas on the Function of the Biceps Brachii Muscle as a Supinator}

turn the hand to the front and to the back without having to rotate the elbow of the arm. The two muscles are wrapped round the bone (radius) in opposite directions, of which when one pulls and unwraps itself, the other wraps itself around the bone like the ropes which revolve a trephine.

Later, probably with the biceps muscle in mind he writes:

that such a rotatory action is especially important in picking up food turning the hand and putting the food in the mouth.

This describes very beautifully the combination of both supination and flexion, performed by the biceps.

This plate in particular, but also others $(2,5)$, indicates that Leonardo understood the function of the biceps, brachialis and pronator teres muscles. Of the other muscles concerned with these movements, one drawing (4) shows that he understood the brachio-radialis muscle to be a flexor of the elbow. The deep muscles of the forearm receive scant attention. The supinator is not shown in any drawing, although the pronator quadratus muscle is hinted at in outline in one plate (5).

To Leonardo da Vinci then, must go the credit for discovering and recording the supinating action of the biceps brachii. The function was certainly not understood by Galen, nor by any of the medieval anatomists writing before Leonardo.

Leonardo died in France in I $^{\text {I9 }}$, and fourteen years later Vesalius published his Fabrica, in I543. It is difficult to understand why this function of the biceps remained unknown to Vesalius, and was not to be described again for 200 years. Although Leonardo did not teach anatomy and never published his notebooks, the oral tradition was strong at this time and he was close friends with at least one anatomist, della Torre, and many of the leading men of art and science of Europe.

\section{Vesalius (1514-64)}

Vesalius, in both editions of his Fabrica, I 543 and I555, discusses the action of the biceps and brachialis muscle.

He quotes Galen as saying that one flexes and moves the forearm inwards so that the hand touches the inner side of the shoulder, and that the other flexes and moves the forearm outwards and the hand touches the outer side of the shoulder. Vesalius points out that Galen contradicted himself in his two books, De Usu Partium and De Anatomicis Administrationibus. Vesalius reinvestigates this problem and finds that each muscle produces straight flexion, however he fails to notice the supinating action of the biceps. The brachio-radialis is described

\footnotetext{
Plate 3-Two sketches of the upper limb, with the biceps, brachialis and pronator teres muscles added, by Leonardo (c. I505) (QII I 9v). This plate is headed, 'On all the forces and action of the muscles of the forearm, that is to say which muscle rotates it, which flexes it.' These two sketches demonstrate beautifully the supinating function of the biceps (see p. 34). The embryological drawings were made between 1510 and 1512 .

Plate 4-A drawing of the flexor muscles of the arm, by Leonardo (c. 1513) (QI I Igr). This drawing shows beautifully the action of the brachio-radialis muscle as a flexor of the elbow.
} 


\section{G. Bearn}

as a supinator, and the structure and function of the supinator and the pronators are correctly given.

Vesalius's Fabrica was by no means the only anatomical work published in the first half of the sixteenth century.

Berengario da Carpi published a commentary on Mundinus in I52I and his own short introduction to anatomy, Isagogae Breves in 1522 . He followed the medieval tradition and ignored any details of the limb muscles. Dryander (1537) and Canano (I54I?) both published illustrated books prior to Vesalius.

That of Canano is worthy of comment.

Canano was made Professor of Anatomy at Ferrara in 154I, when aged twenty-six, and immediately began to issue in parts an illustrated text of anatomy. The first fasciculus was published from Ferrara and is undated, but seems to have been issued in $154 \mathrm{I}$ or at the beginning of 1542 . It consists of twenty-seven plates accompanied by a brief text, each plate showing one muscle in detail, superimposed on the skeleton. The muscles are shown in greater detail and with greater accuracy than in the Fabrica of Vesalius. The book was never completed and even the first volume was suppressed by Canano himself, after Vesalius had visited him in November of $\mathrm{I}_{542}$ and shown him the proofs of his Fabrica.

Estienne, although his book was started in 1536 , was delayed by law suits until I 545, the year of publication. Eustachius's famous plates, prepared at the same time were not published until I7I4, and the text has never been found. Massa published his book without illustrations in 1536 . An examination of the plates and texts of all these anatomists make it clear that none understood the supinating function of the biceps muscle. It is interesting to look at one of Eustachius's plates in detail. In plate 35, the upper limb is shown with the forearm in partial supination. Two muscles are present, the brachio-radialis and the biceps. These two muscles are accurately represented and one may speculate as to whether this was meant to demonstrate the point that the biceps could be considered as a supinator. But as the text is lost, this point cannot be decided. However, such a new idea would certainly have become known to other anatomists had Eustachius understood and taught this function for the biceps, and yet on this point all his contemporaries remain silent, repeating the teaching of Vesalius that the biceps is a straight flexor.

The followers of Vesalius, Columbus (1559) and Fallopius ( 1561 ), both followed Vesalius in their accounts of the biceps muscle, although in other respects making important contributions to anatomy.

Towards the end of the sixteenth century, and in the seventeenth century, many textbooks of anatomy were published. At least fifty-nine books in English appeared between 1548 , when Vicary produced his plagiarism of Lanfranc and de Mondeville, and I 700 (Russell, I 949). Many of these were by British writers, some being translations of books from other countries. Some of the better known ones include Bauhin (1605), Casserius (1627), Spieghel (1627), Vesling (1653), Bartholin (1656), Gibson (1682) who attached the biceps to the ulna, Blancardus (1688), Diemerbroeck (1689) and Keill (1698). 


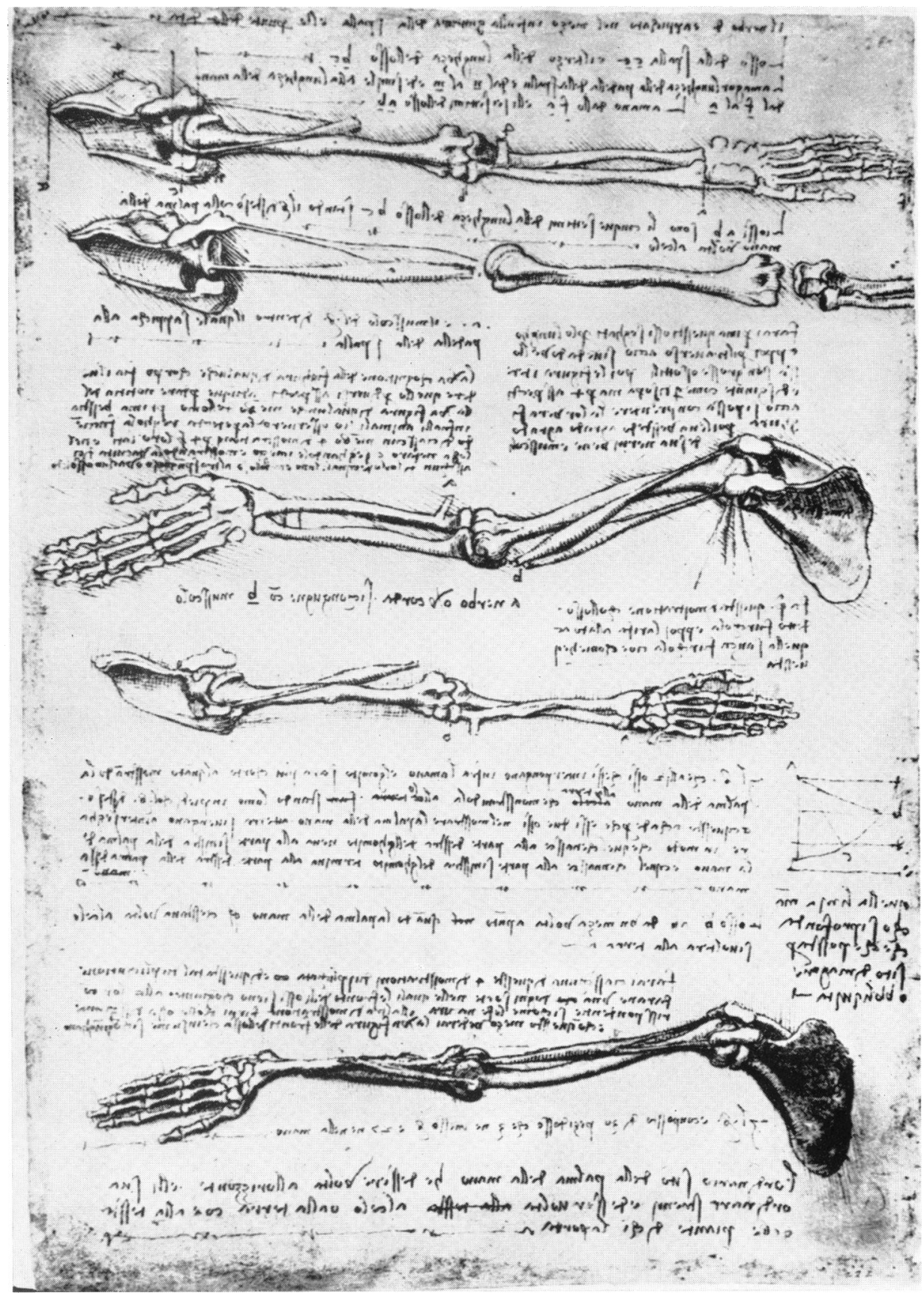

Plate 5 -This plate shows five drawings of the upper limb bones, with the biceps and pronator teres muscles added, by Leonardo ( $c$. I 5 IO) (FA Iv). The pronator quadratus muscle is hinted at in the third sketch. The last drawing shows well the action of pronator teres. 


\section{The History of the Ideas on the Function of the Biceps Brachii Muscle as a Supinator}

Three books on the muscles were produced by John Browne (I68I and I 705) who used plates slightly altered from Casserius (1627); by Cowper ( 1694 and I698), who used Bidloo's plates published in 1685 -in the second edition of I 724 Cowper refers with scorn to Browne's book as 'most erroneous'; and by James Douglas who published in 1707 a small book on the muscles of man and the quadriped.

These many texts have been examined and all follow the traditional view that the biceps is a flexor and the brachio-radialis is a supinator.

\section{Cheselden (I688-1752)}

The first anatomist who gives any hint that he understands that the biceps is also a supinator and the brachio-radialis is a flexor is Cheselden, who published his textbook in I 713, when only twenty-five years of age. In this he says on page 60 that the biceps 'bends the cubit and turns it supine'. Later, on page 66, he says of the brachio-radialis muscle, 'this contributes very much to the bending of the cubit, the hand being turned supine'. He goes on to say that the flexors assist the pronators and the extensors assist the supinators.

Thus Cheselden is the first anatomist to record the supinating action of the biceps, and the flexing action of brachio-radialis.

William Cheselden was born in 1688 , and in 1703 , when only fifteen, became a pupil of William Cowper, and soon after was apprenticed to Mr. Ferne, Surgeon to St. Thomas's Hospital. His progress as an anatomist was rapid. By I 7 I I he was running his own course of anatomy, consisting of thirty-five lectures four times a year, and continued to give these for twenty years, first at his own house and later at St. Thomas's Hospital. He published his first syllabus for these in $\mathrm{I} 7 \mathrm{II}$.

His textbook, which was to become perhaps the most popular one of its time was published in 1713 and ran into many editions, the thirteenth and last published in 1792 in London. Cheselden was taught anatomy by Cowper, who published in 1694 the Myotomia Reformata in London, and in 1698 The Anatomy of Humane Bodies, at Oxford, using Bidloo's plates. Cowper died in I 709, and Cheselden in the preface to his book published in 1713 , makes no reference to his teacher, Cowper, but pays tribute to James Douglas,

that most accurate and indefatigable anatomist whose assistance has been very useful to me in the compiling of this book, and who so obliged the world with an exacter description of the muscles than any extant.

This refers to Douglas's small book on the muscles published in 1707 , which is much inferior to Cowper's books. Neither Cowper nor Douglas describe the biceps as a supinator and we can assume that this was an original discovery of Cheselden.

\section{Winslow (1669-1760)}

Although Cheselden must be given the credit for the first description of the biceps as a supinator in 1713 , Winslow gives a far more detailed and accurate account of the movement. 


\section{G. Bearn}

Jacques-Benigne Winslow was born in 1669 in Denmark, of Swedish origin, and was destined for the Church like his father, first studying theology, but decided to take up medicine, and eventually entered the Faculté in Paris in I 702. He gave the courses in anatomy at the Jardin du Roi, in the place of Duvernay, and later in his own house for many years, and eventually became the Professor of Physick, Anatomy and Surgery in I 743 which he remained until his death at ninety-one in 1760 .

Winslow published his own textbook in Paris in 1732, and an English translation by George Douglas, M.D., F.R.S., brother of James and John Douglas, appeared in 1733 .

In the preface Winslow observes that

Several years ago I was informed, that if I did not publish myself, what I had said and demonstrated in my courses of anatomy, especially those given in my own house, where I often talk without the least reserve, I should have the mortification to find that some other person would do it for me.

\section{He goes on to comment on}

the sincerity of that Gentleman who translated Dr. James Douglas's English myography into Latin, in declaring in his notes that I am the author of several things which I had only mentioned by word of mouth.

This refers to a Latin translation made by Joannes Frederius Schrieber, a Prussian from Königsberg who worked at Leyden under Albino and Boerhaave. It was published in 1729 at Leyden and under the biceps muscle is the footnote 'also supinates the radius and indeed with greater force than its supinatores. Winslow understood this Paris. I 720'. It is interesting to note that a second edition of James Douglas's book was published in I $75^{\circ}$ in Edinburgh but no mention of supination as a function of the biceps is found.

The footnote refers to a paper read by Winslow in 1720 to the Académie Royale des Sciences in Paris on 15 May.

One other anatomist refers to Winslow's observation before the publication of his textbook. This is Lorenz Heister, Professor at Altdorf, who quotes Winslow's paper of 1720 in the second edition of his textbook, Compendium Anatomicum, published in $\mathbf{1} 732$.

Winslow's paper of 1720 is entitled 'De l'Action des Muscles en General, et de L'usage de plusieurs en particulier'. One small paragraph towards the end deals with the biceps, saying that he has found that the biceps is a stronger supinator than the ordinary supinators (i.e. brachio-radialis and supinator), and that it acts principally when the elbow is flexed. He refers to this as a new observation of his own.

In the first edition of his textbook (1732) Winslow deals with this in more detail, the English translation (1 733) by George Douglas reads,

The biceps by its insertion in the radius performs likewise the motion of supination and that with much more force than the muscles commonly assigned for that action by the name of supinatores. 
Later, on the uses of the muscles he enlarges on this point.

The biceps which I likewise name the coraco-radialis . . . moves the forearm in two different manners; that is it bends both bones, and turns the radius upon the ulna; performing both motions by its insertion in the Radius alone.

It is surprising that George Douglas, the translator of Winslow's book, who must have known Cheselden's book, was content to translate Winslow's statement that the biceps is also a supinator 'as I have already shown' without making any comment on the earlier statement by Cheselden. However another brother, John, had quarrelled with Cheselden, and wrote an extraordinary and petty criticism of Cheselden's book on osteology, so this may be a clue to George Douglas's silence on this point.

Winslow also describes the brachio-radialis as a flexor of the elbow, saying it is more fitted for this motion than for supination'. He gives credit to Heister for this observation, referring to the Compendium Anatomicum, published in 1717 and translated into English in $172 \mathrm{I}$. Heister in a footnote states, of the brachioradialis 'May also serve to bend the cubitus'. Heister most probably obtained this information from Cheselden's book of 1713 , to which Heister refers in his preface.

Winslow, although familiar to all students for the foramen, deserves to be better known particularly on account of his studies on the physiology of movement. He is perhaps the first anatomist to discuss groups of muscles performing movements rather than the traditional view of describing the action produced by the contraction of an individual muscle. One example will illustrate this point. It has only recently been emphasized that the supra-spinatus muscle is not merely an abductor of the shoulder, but serves to hold the head of the humerus into the glenoid cavity to prevent upward displacement during contraction of the deltoid. This point is discussed with great clarity by Winslow who even makes the point that the supra-spinatus forms a fulcrum and so enables the deltoid to abduct the arm.

Under the movements of pronation and supination Winslow is also the first to observe that as the lower end of the radius moves round the ulna, this bone moves in the opposite direction.

Winslow was well ahead of his time in his account of muscle action and it is not until 1867 that Duchenne in his classical book on the physiology of movement, continues this work and ushers in the modern era of this field of functional anatomy.

\section{Duchenne (1806-75)}

Guillaume Benjamin Amand Duchenne was born in September 1806 in Boulogne, France; his father was a captain in the French Navy, operating in the English Channel during the times of Napoleon I. He received his early education in a religious school, where he acquired a knowledge of the classical languages and an inclination towards natural science. In 1825 he entered the Medical School of Paris, graduated in 1831 with a thesis on burns. 


\section{G. Bearn}

After graduating, he returned to Boulogne to begin medical practice; he was kind and conscientious and was liked by his patients. In 1835 he became interested in the application of faradic current in the treatment of disease. At the time it was applied by means of platinum needles inserted into tissues, a painful procedure which often produced necrosis. Duchenne found that the application of electrodes to the skin was enough, and soon realized the possibilities of this method in both diagnosis and treatment.

He began an investigation of the muscular response to electrical stimulation and in 1842 migrated to Paris to get better facilities for his research.

His most important book, Physiology of Motion appeared in 1867, and was based on both his clinical observations as well as his experimental electrical stimulation.

He died in 1875 and is rightly regarded as one of the greatest clinicians of a brilliant period of French neurology. He deserves credit for the discovery of locomotor ataxia, progressive muscular paralysis and glossopharyngeal paralysis. Moreover, in 1855 , Duchenne located the lesion of poliomyelitis in the anterior horn of the spinal cord.

His book, Physiology of Motion, must be considered amongst the greatest works on muscle action. He investigated with very few exceptions the entire muscular system correlating his experimental findings with his immense clinical experience of paralysis and deformity. He used not only normal subjects but also fresh cadavers which had still retained the ability to respond to electrical stimulation. He supplemented his research by numerous experiments on animals and by careful anatomical dissections. His approach to the problem is entirely teleological, and he sees a divine purpose in the minutest functional interpretation of every muscle. This perhaps reflects his early religious training.

Modern views on flexion of the elbow joint and the movements of pronation and supination at the radio-ulnar joints stem from the experiments he performed, the electrical stimulation of the muscles and detailed observation of the movements.

The following is an account of his findings taken from Kaplan's translation of his book (1949).

Brachialis. Faradization of the brachialis produces powerful flexion of the forearm without affecting pronation of the radius on the ulna, in other words permitting independent pronation and supination.

Flexion is produced directly without lateral deviation.

Biceps. (Flexor supinator.) With the hand in pronation, the electrical stimulation of the biceps produces immediate supination and simultaneous flexion of the forearm. If while the biceps is thus in contraction by a strong current, an attempt is made to produce pronation, there is strong resistance to this attempt.

Brachio-radialis. Electrical stimulation produces powerful flexion of the forearm. Simultaneously it places and maintains the hand between pronation and supination. However the pronation produced is less extensive than the supination produced by the biceps.

Supinator. Stimulation produces powerful and complete supination, independent of all other movements.

Pronator teres. Pronator quadratus. Electrical stimulation produces powerful pronation. Pronator teres also flexes the forearm, either if pronation is complete or resisted, but with little force. 
He goes on to say that previously only two muscles were considered to produce flexion, i.e. biceps, brachialis, and that it is surprising that anatomists had not found earlier that the brachio-radialis muscle is a powerful flexor of the forearm, especially as the muscle is visible during flexion against resistance, especially if the hand is in pronation.

He then goes on to say that it was considered previously that only two muscles pronated and two muscles supinated the forearm. His electrical stimulations have confirmed the action of three, pronator teres, pronator quadrater, and supinator, but in the case of the brachio-radialis, the main action was flexion of the elbow, and to place the forearm midway between pronation and supination, and that the biceps is a powerful supinator. This is summarized by saying that the brachialis is an independent flexor, the biceps is the flexor supinator and brachio-radialis is the flexor pronator, and that the remaining three muscles, the supinator, the pronator teres and the pronator quadratus are independently supinator and pronators.

There is little in this account with which the modern anatomist or physiologist would disagree, except perhaps the name 'flexor pronator' for brachio-radialis, but even here, Duchenne recognizes that the muscle brings the forearm into the mid-position between pronation and supination. Duchenne mentions that Winslow described the biceps as a powerful supinator, and also gives him credit for describing the brachio-radialis as a flexor of the elbow.

It is now an accepted part of anatomical teaching that during pronation and supination some movement of the ulna takes place. Duchenne makes this point clearly and gives credit to both Winslow and to Vicq d'Azyr for earlier accounts demonstrating that the movement of the radius is accompanied by opposite movement of the ulna.

One final question remains unanswered. Could either Cheselden or Winslow have had access to Leonardo da Vinci's drawings? Exactly when the anatomical drawings became a part of the Royal Collection is not known, but certainly by I69o they were in Kensington Palace, when Queen Mary showed them to Constantign Huygens. It is William Hunter who seems to be the first anatomist to study them, and he speaks of them with enthusiasm and announces his intention to publish them. This was prevented by his death in 1783 and the first selection of anatomical drawings to appear was not until 1796 , by John Chamberlaine, in his Imitations of Original Designs by Leonardo da Vinci.

\section{ACKNO WLEDGMENTS}

The author is indebted to the late Dr. Charles Singer for advice in the preparation of this paper, and to Dr. F. N. L. Poynter and the Staff of the Wellcome Historical Medical Library for their unfailing help, and to Dr. Charles O'Malley for permission to quote from his translation of Leonardo da Vinci's text. 


\section{G. Bearn \\ REFERENCES}

Avicenna (1925). Quoted in The Evolution of Anatomy by Charles Singer.

Bartholin, T. (1656). Anatomia. Dordrecht.

Bauhin, C. (1605). Theatrum Anatomicum. Frankfort-am-Main.

Berengario, J. (i959). Isagogae Breves. Trans. L. R. Lind, Chicago.

Blancardus, S. (1688). Anatomia Reformata. Leyden.

Browne, J. (168I and I705). A Compleat Treatise of the Muscles.

Canano, I. B. (I 541?). Musculorum Humani Corporis Picturata Dissectio. Ferrara.

Casserius, J. (1627). Tabulae Anatomicae. Venice.

Gheselden, W. ( 7 I3). Anatomy of the Humane Body.

Cheselden, W. (1 733). Osteographia.

Columbus, R. (1559). De re Anatomica. Venice.

CoWPER, W. (1694). Myotomia Reformata. London.

Cow PE R, W. (1698). The Anatomy of the Humane Bodies. Oxford.

Diemer BR OE G K, I. De (1689). The Anatomy of Human Bodies.

Douglas, J. (I 707). Myographiae Comparatae Specimen.

Douglas, J. (1 729). Myographiae Comparatae Specimen. Trans. into Latin by J. F.

Schreiber, Leyden.

Dryander, J. (1537). Anatomiae. Marpurgi.

Duchenne, G. B. A. (1867). Physiologie des Mouvements. Paris.

Duchenne, G. B. A. (1949). Physiology of Motion. Trans. and Ed. E. B. Kaplan, Philadelphia.

Estienne, G. (I 545). De Dissectione partium corporis humani. Paris.

Eustacchi, B. (1 7 14). Tabulae Anatomicae. Rome.

Fallopius, G. (I 56I). Observationes Anatomicae. Venice.

Gale N (1822). De Usu Partium. Ed. G. G. Kühn, 3, r 54. Leipzig.

Gale n (1956). On Anatomical Procedures. Trans. Charles Singer.

Gibson, T. (1682). The Anatomy of Humane Bodies Epitomised.

Heiste R, L. ( I 7 I 7 ). Compendium Anatomicum. Nuremberg and Altdorf.

KeILl, J. (1698). The Anatomy of the Humane Body Abridged.

Massa, N. (1536). Anatomiae liber introductorius. Venice.

Mundinus (1925). The Fasciculo di Medicina, containing 'The Anatomy of Mundinus'. Trans. Gharles Singer. Florence.

Russel , K. F. (1949). A bibliography of Anatomical Books published in English before 1800 . Bull. Hist. Med., 23, 268.

S Pieghel, A. (1627). De Humani Corporis Fabrica. Venice.

Vesalius; A. (I543 and i 555). De Humani Corporis Fabrica. Basel.

Vesiing, J. (1653). The Anatomy of the Body of Man.

Vicary, T. (r577). A profitable Treatise of the Anatomie of Man's Body.

Vinci, L. DA (1952). Leonardo da Vinci on the Human Body. Trans. Charles D. O'Malley and J. B. de C. M. Saunders. New York.

Winslow, J.-B. (1 720). De l'Action des Muscles en Général, et de l'usage de plusieurs en particulier. Histoire de l'Académie Royale des Sciences. 85. Paris.

Winslow, J.-B. (1 732). Exposition Anatomique de la Structure du Corps Humain. Paris.

Winslow, J.-B. (I 733). An Anatomical Exposition of the Structure of the Human Body.

Trans. G. Douglas, M.D. 